\title{
ESTUDIO TECNOLÓGICO PARA LA ELABORACIÓN DE HOT DOG A PARTIR DE LA CARNE DE CUY*
}

\author{
Espinoza Silva, Clara Raquel${ }^{1}$ y Solís Rojas, José Luis ${ }^{2}$ \\ Facultad de Ingeniería en Industrias Alimentarías, Universidad Nacional del Centro del Perú
}

\begin{abstract}
RESUMEN
El cuy doméstico representa una fuente valiosa de carne en las zonas rurales del país, en la actualidad se cría en granjas y por lo tanto es una fuente proteica que puede muy bien ser aprovechada en la elaboración de hot dog ya que por un lado se incrementa su valor comercial y por otro lado este producto tiene gran facilidad de consumo por ser de rápida preparación. Los objetivos de la investigación fueron: Determinar el porcentaje óptimo de carne de cuy para la elaboración de hot dog. Evaluación del análisis organoléptico del hot dog de carne de cuy. Para la elaboración del producto se siguió el siguiente diagrama de flujo: selección, picado, cutter, embutido, escaldado, enfriado, escurrido, conservación y comercialización. Se trabajo con carcasa de cuy a un $\mathrm{pH}$ de 6,34, realizándose pruebas de Eber, Nessler y ácido sulfhídrico que son indicadores de putrefacción de carnes dándonos un resultado negativo. Se llegó a determinar el contenido de grasa que fue de 7,4\% y determinándose el porcentaje óptimo de carne de cuy en la formulación como producto aceptable se tuvo el T2 quien ocupa el primer lugar por la consistencia apariencia, olor y sabor del hot dog teniendo como resultado final carne de cuy $90 \%$ y proteína de soya $10 \%$ el cual se obtiene en función a un análisis organoléptico.
\end{abstract}

Palabras clave: Cuy, hot dog, cutter, embutido, escaldado

\section{TECHNOLOGICAL STUDY FOR MAKING HOT DOG STOITICY FROM GUINEA PIG MEAT}

\begin{abstract}
The present investigation litled "A Technological study for the elaboration of hot dog starting from guinea pig meat " has four objectives; to determine the good \% of guinea pig meat for the elaboration of hot dog to evaluate through an organoleptic analysis. The guinea pig meat represents a valuable source of meat in the rural areas of the country and at the present it's raised in farms therefore, it's a great source of proteins which can be profitable in the elaboration of the hot dog, for one reason it increases its commercial value and for another this product has a great facility in the consumption and quick preparation. For the elaboration of this hot dog, we followed the present diagram of flow: selection, diving cutting , cooling sausage, sealding, draining, conservation, commercialization. You work with guinea pig carcosa, We worked a 6,34 ph carring out test Eber Nessler and sulphidric acid that are indicatives of the rotting of this moet giving us a negative percentage. It was determined that the content of fat was 7,45\% and being determined the \% percent of good guinea pig meat in the formulation as an acceptable meat. We got T2 that takes the first place for its consistence, appearence, color and flavor of the hot dog and having as a final result, $90 \%$ of guiena pig meat and soy protein in $10 \%$ which is obtained as a result of an organoleptic analysis.
\end{abstract}

Key word: Cuines pig , hot dog, cutter, sausage embutido, escaldado enredished

\section{INTRODUCCIÓN}

El cuy a través de muchos siglos desde las épocas de vida silvestre pasó a su estado doméstico por la exquisitez de su carne, por ser un animal de fácil adaptación a la crianza y selección, existiendo en la actualidad varios tipos de cuy que nos ofrecen ventajas en cuanto a sus características anatómicas.

Actualmente, en nuestro país se está revalorando esta carne por su valor nutritivo como 19,1\% de proteína aproximadamente y se busca nuevas alternativas de

\footnotetext{
* Este trabajo de investigación fue recibido el 20/10/2006 retornado para su revisión 20/06/2007 y aprobado para su publicación 10/12/2007

1. E-mail: cespinoza_silva@hotmail.com

2. E-mail: jotita23@hotmail.com.; luis_an28@yahoo.es
} 
consumo y su uso en diferentes platos típicos. Una forma de aprovechar esta carne tan deliciosa y nutritiva es elaborar productos cárnicos usando la tecnología como lo demuestra el presente trabajo de investigación en la elaboración de hot dog a partir de carne de cuy. Pese al costo que representa tenemos la alternativa de usar este recurso en un embutido escaldado. Los objetivos fueron: Determinar el porcentaje óptimo de carne de cuy para la elaboración de hot dog y evaluar la aceptabilidad del producto mediante análisis sensorial.

\section{MATERIAL Y MÉTODOS}

\section{Lugar de ejecución}

Se realizó en los laboratorios de: Tecnología de Alimentos de la Facultad de Ingeniería en Industrias Alimentarías UNCP,

\section{Materia prima}

Carcasa de cuy (tipo I)

\section{Material y equipos}

\section{Materiales de laboratorio:}

- $\quad$ vasos de precipitación de $250 \mathrm{~mL}$.

- termómetro $0^{\circ} \mathrm{C}$ a $100^{\circ} \mathrm{C}$.

- $\quad$ piceta

- $\quad$ pinzas de acero

- $\quad$ bureta de $25 \mathrm{ml}$

- bagueta de vidrio

- $\quad$ tripas naturales

- pita

- menaje de cocina

- otros

\section{Reactivos:}

- $\quad$ sal de cura

- fosfatos

- azúcar

- sal común

- colorantes

\section{Equipos:}

- refrigeradora

- balanza analítica

- licuadora industrial

- embutidora

- moledora de carne

- otros

\section{Metodología experimental}

Se siguió el siguiente diagrama de flujo para la elaboración de hot dog a partir de carne de cuy.

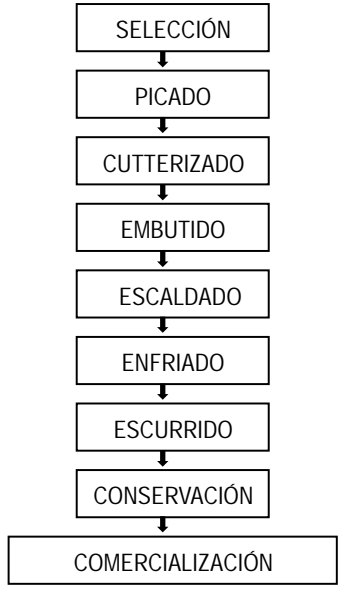

Figura 1.- Diagrama de flujo para la elaboración de hot dog a partir de carne de cuy.

\section{Método de determinación de pH en la carne de cuy}

- Pesar 10 g de muestra

- Enrasar a $100 \mathrm{ml}$ con agua destilada y moler en la licuadora durante un minuto

- Estandarizar el pH en el potenciómetro con buffer de fosfatos con $\mathrm{pH}=6,0$

- Filtrar la mezcla de carne con un papel filtro para eliminar tejido conectivo

- Después de leer el pH de la carne, enjuagar el electrodo con agua destilada.

- Para la determinación del pH de la carne de cuy se tomaron muestras de las distintas partes de la carcasa hasta llegar a 10 gramos para determinar el $\mathrm{pH}$.

\section{Determinación de grasa}

\section{Método butirométrico}

- Pesar $3 \mathrm{~g}$ de la muestra previamente molida y homogeneizada en el vaso especial del butirómetro.

- Añadir ácido sulfúrico en solución a 50\% en el butirómetro hasta completar el vaso que contiene la muestra, después de la cual se cierra con un tapón de goma y se coloca a baño maría, a temperaturas entre $65^{\circ} \mathrm{C}-70^{\circ} \mathrm{C}$, durante $20 \mathrm{~min}$. En este tiempo se toma el butirómetro 3-4 veces y se agita.

- $\quad$ Pasado este tiempo se extrae el butirómetro y se le añade $1 \mathrm{ml}$ de alcohol amílico y ácido sulfúrico solución a 50\%, hasta la marca 35 del butirómetro. Después de esto se tapa y se agita, virándolo varias veces.

- Colocar nuevamente a baño maría durante 5 minutos, a la misma temperatura, y pasado este tiempo se centrífuga $5 \mathrm{~min}$. Después de la 
centrifugación se coloca sin agitación el butirómetro a bañomaría durante $5 \mathrm{~min}$. leyéndose posteriormente el porcentaje de la grasa separada en la escala.

\section{RESULTADOS}

\section{Características de la calidad de las carcasas de cuy}

Para la elaboración de hot dog tenemos que caracterizar la carne de cuy y evaluar la frescura de dicha carne, ya que estos parámetros nos determinaran una buena capacidad de retención de agua que es básico para la elaboración del hotdog.

Cuadro 1.- Pruebas de putrefacción de la carne de cuy

\begin{tabular}{|c|c|}
\hline PRUEBAS & RESULTADO \\
\hline Eber & No emisión de gas (negativo) \\
\hline Nessler & $\begin{array}{l}\text { La coloración del reactivo fue de color } \\
\text { amarillo sin variación (negativo) }\end{array}$ \\
\hline Ácido sulfhídrico & $\begin{array}{l}\text { La muestra no manchó } \\
\text { el papel de color alguno (negativo) }\end{array}$ \\
\hline
\end{tabular}

\section{Determinación del porcentaje de grasa}

Se tomaron muestras de:

2/4 de carcasa posterior: 7,3

2/4 de carcasa anterior: $\quad 7,5$

Promedio $7,4 \%$ de grasa

\section{Evaluación de análisis organoléptico}

Se trabajo con un panel de jueces expertos de ambos sexos, El diseño experimental consiste en 5 tratamientos con 2 repeticiones, los factores de estudio tomados en consideración fueron:

- Carne de cuy

- Proteína de soya

- Carne de cerdo

Cuadro 2.- Determinación del porcentaje óptimo de carne de cuy

\begin{tabular}{lccccr}
\hline Componente & T1 & T2 & T3 & T4 & T5 \\
\hline Carne cuy & $100 \%$ & $90 \%$ & $80 \%$ & $70 \%$ & $80 \%$ \\
Proteína de soya & 0 & $10 \%$ & $20 \%$ & $30 \%$ & 0 \\
Carne de cerdo & 0 & 0 & 0 & 0 & $20 \%$ \\
\hline
\end{tabular}

\section{Determinación del porcentaje óptimo de carne de cuy}

El porcentaje óptimo para la elaboración de hot dog es de: carne de cuy $90 \%$ y proteína de soya $10 \%$, si se aumenta la proteína de soya queda el sabor de la soya por lo que no es conveniente la adición de mayor cantidad de la misma. Por otro lado dicho insumo le da más consistencia al producto aumentando su capacidad de retención de agua y mejorando las características organolépticas del producto.

\section{Determinación de la eficiencia del cutter y embutidora manual}

Eficiencia del picado en la cutter: 0,99

Eficiencia de la embutidora manual: 0,81

\section{DISCUSIÓN}

Características de la calidad de la carcasa de cuy. Las pruebas de putrefacción que se hicieron a la carne de cuy demostraron que estuvo en un buen estado de conservación y que no hubo putrefacción de dichas carnes. La putrefacción constituye la más importante alteración de la carne: considerada en el orden biológico. La putrefacción es un fenómeno natural, una de las fases de la descomposición de la materia albuminoidea (Price, 1995).

Así, a medida que se pudre la molécula albuminoidea se transforma, primero, en albuminosa y peptona; después origina numerosos compuestos, gases, ácidos orgánicos, amidas, etc. El proceso de la putrefacción también alcanza a las grasas y carbohidratos (Price, 1995).

Al proseguir la descomposición, pueden los aminoácidos, como consecuencia de la acción fermentativa, transformarse en aminas desprendiendo anhídrido carbónico (decarboxilación o bien desprenden amoniaco (bacterias anaerobias) con frecuencia tiene lugar también la hidrólisis (desdoblamiento mediante fijación de igual de los aminoácidos bacterias aerobias) (Sanz, 1997).

Los productos intermedios y finales de naturaleza proteica que se forman en la descomposición (putrefacción) son muy numerosos. Además de los compuestos químicos ya mencionados pueden evidenciarse también los siguientes: metano, hidrógeno, nitrógeno, hidrógeno sulfurado, ácidos orgánicos, amidas, peptonas, etc. (Price, 1995).

\section{Determinación del porcentaje de grasa}

La composición de la grasa depende de la especie, alimentación y edad. Cuando un animal come más alimento del que necesita para mantenerse y proporcionarle energía para vivir y moverse, se convierte en grasa que comienza a acumularse en los tejidos corporales (Téllez, 1990).

Las grasas animales suelen ser ricas en los ácidos esteáricos, palmitito y oleico aunque contiene también pequeñas cantidades de otras grasa. El contenido de 
acumulación de algunas grasas de animales varía un poco dentro de una misma especie animal debido a factores tales como: la dieta y el ambiente, los elementos metálicos presentes en la dieta, afectan también la composición de la grasa y a sus propiedades. Los suplementarios de cobre pueden también determinar el ablandamiento de la grasa de los cerdos en crecimiento. El tipo de ácidos grasos del tejido muscular, también depende de la especie, así la grasa de las aves es más insaturada que la del cerdo que a su vez, lo es más que del ganado vacuno u ovino (Tellez, 1990).

\section{Evaluación del análisis organoléptico}

Los tratamientos fueron sometidos a degustación, considerando los factores de consistencia, apariencia, olor y sabor del producto, para ello se contó con la participación de 20 jueces no entrenados, en el que dieron sus respectivas calificaciones considerando la escala de puntuaciones de 1 a 7 .

Como resultado de la tabulación de datos y la aplicación del análisis de variancia (ANVA), se tuvo que, en la fuente de variación de productos existen diferencias significativas mínimas en lo referente a los tratamientos, lo que indica que no hay variación sensorial entre los productos. Como producto aceptable se tuvo el T2 quien ocupa el primer lugar por la consistencia apariencia, olor y sabor del hot dog.

Cuando hablamos del desarrollo del color en el hot dog, podemos afirmar que el tiempo requerido para que el nitrito se convierta en óxido nítrico y se cueza el producto a una temperatura interna mínima de $71^{\circ} \mathrm{C}$ si alcanza temperaturas mayores se producen defectos internos en las tripas (Téllez, V., 1990).

El factor de mayor importancia en la preparación de emulsiones estables es la extracción de la proteína muscular (Price, 1995) que se puede aumentar con una proteína no cárnica, también se puede preparar una emulsión de carne en estado pre-rigor, congelar la carne y añadir sal a la carne en este estado y mantenerla a baja temperatura.

\section{CONCLUSIONES}

- La carcasa de cuy no presentó indicios de putrefacción debido a que todas las pruebas de deterioro fueron negativas.

- El pH promedio de la carcasa de cuy fue de 6,34 y el porcentage de grasa fue de $7,4 . \%$

- El diagrama de flujo seguido para la elaboración de hot dog es: selección, picado, cutter, embutido, escaldado, enfriado, escurrido, conservación, comercialización.

- El porcentaje óptimo de carne de cuy es $90 \%$ y proteína de soya $10 \%$.

- La eficiencia del picado en la cutter fue de 0,99 y la embutidora manual de 0,81.

- $\mathrm{A} 71^{\circ}$ de temperatura se elimina la carga microbiana.

- El tiempo de almacenamiento fue de 45 días a temperatura de refrigeración.

\section{LITERATURA CITADA}

Price, J. 1995. Ciencia de la carne y de los productos cárnicos. Acriba. Zaragoza, España.

Sanz Egaña 1997. Enciclopedia de la carne. Acribia. Zaragoza, España.

Téllez Villena, J. 1990. Tecnología e industrias cárnicas. Tomo Iy ll. Artes

Wilson, A. 1990. Inspección de prácticas de la carne. Acribia. Zaragoza, España

Zevallos San Martín, D. 1990. El cuy su cría y explotación. Editorial ENCAS. 